Hajrudin Hodžić, prof.

IMAM EL-EVZA'I - ZASJENJENI FIKHSKI VELIKAN (88157. H.G.)

Sažetak:

Ovaj rad obrađuje biografiju i naučni opus jednog od najvećih islamskih učenjaka i fakiha svoga vremena imama El-Evza ija.

Pored govora o njegovom životnom putu i renomeu, izdvojili smo izreke njegovih savremenika o njemu, govorili o njegovim učiteljima $i$ učenicima, a na kraju smo naveli nekoliko primjera njegove odvažne i stabilne ličnosti.

Jedan od glavnih zadataka ovoga rada je pokušaj da se odgovori na pitanje: Zašto je iščezao mezheb imama El-Evza ija iako je njegov osnivač bio jedan od najvećih i najpriznatijih fakiha.

Vrijednost ovoga rada je u činjenici da je o velikanima islama na našem jeziku pisano jako malo, a da se o islamskom velikanu, kakav je imam El-Evza i, još manje znalo.

Uvod

Izučavanje životopisa islamskih učenjaka je od velike koristi, naročito ako se radi o osobi poput imama El-Evza'ija, koji je uspio objediniti nauku i praksu, teoriju i suštinu. Izučavati učenjaka njegovog renomea predstavlja izazov za svakog istraživača, posebno ukoliko se zna da se o njemu jako malo pisalo, a da je pored toga, kako to kaže Salih b. Jahja u djelu Tarihu Bejrut, "uživao veliki ugled u Šamu do te mjere da je bio ugledniji od sultana. “1

Prilikom svog istraživanja nisam imao dovoljno literature na ovu temu, pa sam se koristio, pored postojeće, internet stranicama i raznim tekstovima.

${ }^{1}$ Zirikli Hajruddin, El-E`lam, str. 3/320, Darul-ilm lil-melajîn, 11. izdanje, Bejrut, 1995. 
S obzirom da na bosanskom jeziku nemamo velik broj djela koja govore o velikanima islama uopće (osim djela Velikani islama, Velikani hadiskih znanosti i Velikani tefsirskih znanosti), želja mi je bila da uzmem učešća u osvjetljavanju biografija prethodnika ovoga ummeta i da svojom studijom obogatim materiju koja obrađuje ovu tematiku na bosanskom jeziku.

\section{Cilj rada}

Cilj ovoga rada je da kroz sažetije izlaganje prikaže osnovne crte života i naučno-intelektualnog rada jednog od velikana islamskih nauka i jednog od muslimanskih prvaka kakav je imam El-Evza'i.

Cilj mi je osvjetliti ličnost ovog uglednog učenjaka i praktikanta kako bi njegov životopis bio još jedan u nizu životopisa islamskih velikana o kojima je izuzetno malo pisano na bosanskom jeziku.

Jedan od konkretnijih zadataka jeste težnja da odgovorim na pitanje zašto je njegov mezheb iščezao i nestao, mada će moja potraga za odgovorom biti u znatnoj mjeri nepotpuna zbog oskudnosti dostupne literature koja je usko vezana za pitanje koje istražujem.

Zašto sam se opredijelio za ovaj rad?

Često sam od svojih cijenjenih profesora u Damasku slušao izreku u kojoj se kaže da je imam El-Evza'i bio veći fikhski stručnjak od svih ostalih fikhskih velikana po kojima su islamske pravne škole dobile ime, ali da njegovi stavovi, njegov mezheb i naučni opus nije stigao do nas iz razloga što njegovi učenici, kakve su i ostali fikhski velikani imali, nisu to prenijeli narednim generacijama.

Poveden tom izrekom želio sam da se, koliko je to u mojoj mogućnosti, upoznam sa njegovim životom i zavidnim naučnim opusom, pa da to na kraju i drugima prenesem. 
Puno ime imama El-Evza'ija je Abdur-Rahman b. 'Amr b. Juhmed, Ebu 'Amr el-Evza'i. Kod Španaca je bio poznat kao Auzü i Aowzei, kako to ističe Hajruddin Zirikli u svom El-E'lamu'.

Rođen je u Ba'lebekku³ (Liban) 80. godine po Hidžri, kao jetim. Majka ga je prenosila iz jednog mjesta u drugo ${ }^{4}$, tako da je još u djetinjstvu obišao mnogo sela i gradova dok se nisu nastanili $u$ Bejrutu.

Hafiz Ibn Kesir, pak, prenosi od Ebu Zur'e er-Razija da je porijeklo imama El-Evza'ija iz Sinda, oblasti u zapadnom Pakistanu, mada za to ne postoji relevantan dokaz.

Dr. Muhammed Buzugajbe sa Univerziteta Ez-Zejtuna navodi podatak da ga je odgajao i brinuo se o njemu jedan od očevih prijatelja da bi ga, nakon što je postao punoljetan, zaposlio u Registar. ${ }^{6}$

Biografi se ne slažu oko toga zbog čega je postao poznat kao 'El-Evza'i', pa tako Zirikli tvrdi da je to zbog pripadnosti plemenu po imenu El-Evzâa ${ }^{6}$, dok imam Buhari i Ibn Kesir u svom kapitalnom djelu El-Bidajetu ven-nihaje tvrde da je to zbog činjenice da je odsjeo u okolini Damasku u selu zvanom El-Evzâ', koje se nalazi izvan jednih od sedam vrata starog Damaska po imenu Babul-Feradîs ${ }^{8}$.

Veći dio svoga života provodi u Bejrutu kao asketa i branitelj muslimanskih granica, zajedno sa svojom porodicom i djecom.

Danas njegovo ime nosi bejrutski univerzitet 'Univerzitet imam El-Evza 'i', na kojem se izučavaju vjerske i svjetovne nauke.

Postoje razilaženja oko godine njegove smrti, međutim, kako tvrdi Ibn Kesir, umro je krajem mjeseca safera 157. h. godine u Bejrutu. $^{10}$

\footnotetext{
${ }^{2}$ El-E'lam, str. 3/320.

3 Ez-Zehebi Šemsuddin, Sijer e'lamin-nubelâ', 7/107, fusnota, Muessesetur-risale, (jedanaesto izdanje), Bejrut.

${ }^{4}$ Ibn Kesir Ebul-Fidâ', El-Bidajetu ven-nihaje, Darul-hadis, Kairo, 1993, str. 10/124.

${ }^{5}$ El-Bidajetu ven-nihaje, str. 10/124.

${ }^{6}$ Dr. Buzugajbe Muhammed, Siretul-imam El-Evza $i$, www. middleeasttransparent. com

${ }^{7}$ El-E'lam, str. 3/320.

${ }^{8}$ El-Bidajetu ven-nihaje, str. 10/124.

9 Ova četvrt Damaska danas je poznata kao Babul-'Amara (Sijer e'lamin-nubelâ', 7/107, fusnota).

${ }^{10}$ El-Bidajetu ven-nihaje, str. 10/129.
} 
Ako pogledamo doba u kojem je živio ovaj ugledni imam, shvatićemo da je rođen u vrijeme kada je jedan broj drugova Allahovog Poslanika, s.a.v.s., bio još uvijek živ, te mu to daje posebnu čast da se susretne ako ne s njima, onda sa tabi'inima, tj. ljudima koji su ih susreli i živjeli sa njima, iako nisu drugovali sa Allahovim Poslanikom, s.a.v.s.

Ta činjenica nam dovoljno kazuje koliko je nauka koju je stjecao imam El-Evza'i bila čista, bliska izvoru i nepomućena. Upravo zbog toga su skoro svi njegovi učitelji i osobe od kojih je prenosio hadise bili, upravo, tabi 'ini koji su imali direktan kontakt s ashabima, drugovima Allahovog Poslanika, s.a.v.s.

Imam El-Evza'i je, također, živio u periodu vladavine dviju dinastija, emevijske i abbasijske. Bio je savremenik devet emevijskih i dvaju abbasijskih halifa ${ }^{11}$, što je za učenjaka njegove reputacije predstavljalo veliki izazov s obzirom da se stavovima učenjaka toga vremena pridavala velika pažnja. Njihove riječi su bile orijentir običnom puku kako da se postavi spram raznih društvenih kretanja.

To je za njega predstavljalo i veliku odgovornost. Pozicija imama El-Evza‘ija je poput pozicije između okova i nakovnja, gdje s jedne strane postoji pritisak koji vrši vlast i prijeti strogim kaznama, a $\mathrm{s}$ druge narod koji će se povoditi za njegovim postupcima u vezi s određenim pitanjima.

Činjenica da je živio u uzburkanom političkom vremenu često ga je stavljala pred skoro nerješive dileme - kako se postaviti spram postojeće vlasti i kako, u isto vrijeme, sačuvati čast i dignitet osobe za kojom se povode narodne mase.

Imam El-Evza'i je tu prepreku i izazov znalački znao prevazići i ostati omiljen Bogu i narodu. Ibn Kesir u svojoj El-Bidaji ven-nihaji navodi podatak da su ga neki vlastodršci htjeli likvidirati, pa su ih njihovi savjetnici posavjetovali kazavši im: "Okanite se toga! Tako nam Allaha, kada bi imam El-Evza'i naredi stanovnicima Šama da te ubiju, oni bi te ubili. “'12

\footnotetext{
${ }^{11}$ Siretul-imam El-Evza $i$, www.middleeasttransparent.com

${ }^{12}$ El-Bidajetu ven-nihaje, str. 10/128.
} 


\section{Njegovi učitelji i učenici}

Jedna od karakteristika velikana različitih islamskih nauka jesu i naučne ekspedicije koje su tada, u odsustvu savremenih naučnih pomagala, bile nerazdvojne metode svakog naučnog velikana.

Tako je i imam El-Evza'i putovao i sticao nauku od učenjaka Šama, Iraka te Mekke i Medine. Od najistaknutijih su bili 'Ata b. Ebi Rebah i Ibn Šihab ez-Zuhri. Uz ova dva zvučna imena spominju se i Katade, Nafi‘a, Ibn Omerov štićenik, Muhammed b. el-Munkedir i dr. $^{13}$

Imam El-Evza'i je imao i svoje učenike. Od najistaknutijih i najblistavijih imena koja su imala priliku učiti od imama El-Evza'ija jesu Sufjan b. 'Ujejne i Veki' b. el-Džerrah. ${ }^{14}$ Tu su i Malik b. Enes i Sevri.

Zanimljivo i bitno je istaći da prilikom izučavanja biografije imam El-Evza'ija nailazimo i na to da je, pored svojih učitelja i učenika, imam El-Evza'i imao osobe koje su, pored što su bili njegovi učenici, bili i njegovi učitelji, ili obratno. Drugim riječima, imam ElEvza'i se nije dvoumio, kada je u pitanju nauka, uzimati je i od svojih učenika, sjedeći pred njima kao pred svojim uvaženim učiteljima, što ukazuje na njegovu poniznost, skromnost i opredijeljenost na putu sticanja nauke.

\section{Pisana djela}

Navodi se da su iza imama El-Evza'ija ostala četiri djela:

- Sunen - djelo o fikhu,

- Musned - djelo o fikhu,

- jedno djelo o fetvama $\mathrm{i}$

- djelo o sijeru, u kojem govori o odnosima muslimana sa nemuslimanima za vrijeme rata. ${ }^{15}$

Ovaj podatak spomenuo je dr. Muhammed Buzugajbe, ali ova djela ne spominje više niko drugi. Jedino djelo koje je dostupno

\footnotetext{
${ }^{13}$ El-Kejlani Ismail, Abdur-Rahman el-Evza'i, el-alimul-murabit, www.fustat.com/ bibliography/ awzai. shtml

${ }^{14}$ Siretul-imam el-Evza $i$,www.middleeasttransparent.com

${ }^{15}$ Siretul-imam el-Evza $i$,www.middleeasttransparent.com
} 
čitalačkoj publici jeste El-Evza'ijev sunen, koji je, ustvari, zbirka hadisa, predaja i fetvi što ih imam El-Evza'i prenosi, a koji je naučno obradio i valorizirao šejh Muhammed eš-Ša'ar i nakon toga poredao po fikhskim temama.

\section{Nekadašnja rasprostranjenost njegovog mezheba}

Mezheb imama El-Evza'ija je bio zadugo rasprostranjen $u$ Šamu, zemljama arapskog Magriba i Andaluziji. Tako je u Šamu bio dominantan do 340, a u zemljama Magriba i sjevere Afrike do 197. hidžretske godine. ${ }^{16}$ Zadnji koji je sudio prema njegovom mezhebu je bio kadija Ahmed b. Sulejman b. Hazlem.

Mišljenja imama El-Evza'ija su bila mjerodavna i prema njima se sudilo u muslimanskoj Andaluziji sve do vladavine El-Hakem b. Hišama. ${ }^{17}$ Nakon toga, usljed nepostojanja kodifikacije njegova mezheba, ovaj mezheb iščezava i prestaje se prakticirati u ostatku islamskog svijeta.

Šta se desilo sa njegovim mezhebom?

Možda je najveći razlog zbog kojeg sam se odlučio na ovaj rad upravo ovo pitanje.

Nakon istraživanja stigao sam do nekoliko razloga zbog kojih je iščezao mezheb jednog od najvećih fikhskih velikana islama. Ono što ću nabrojati može samo poslužiti kao pretpostavka, a nikako kao utvrđene činjenice, jer nijedna od njih se ne može argumentovano dokazati kao razlog iščezavanja njegovog mezheba.

Te razloge bih mogao ukratko ovako elaborarirati:

1. Imamove stavove ili mezheb niko od njegovih učenika nije zabilježio, nego su to usmeno prenosili, pa je vremenom iščeznuo. I dan-danas u pojedinim fikhskim djelima mogu se pronaći neki njegovi stavovi, ali to što je zabilježeno, ne može se smatrati cjelovitim mezhebom poput ostalih mezheba, koji o svakom bitnijem pitanju imaju svoj stav i argument na kojem se isti stav zasniva.

\footnotetext{
${ }^{16}$ Siretul-imam el-Evza $i$,www.middleeasttransparent.com

${ }^{17}$ El-E'lam, str. 3/320.
} 
2. Postojala je želja pojedinih učenika imama El-Evza'ija da čuju i drugačija mišljenja od tada živih fikhskih velikana poput Malika, Šafije i drugih. ${ }^{18}$ Drugim riječima, njihova nepresušna želja koju je u njih zasadio imam El-Evza'i ponukala ih je da nastave svoju potragu za istinom i jačim stavovima, $\mathrm{s}$ dužnim poštovanjem prema stavovima koje su čuli od velikana kakav je imam El-Evza‘i.

Bitno je napomenuti da je ovo jedna od odlika učenika imama El-Evza'ija, a nikako manjkavost. Slijepi fanatizam je pokuđen i ne priliči učenjaku i objektivnom istraživaču, a potraga za istinom i argumentovanim stavom odlika je nepristrasnih, objektivnih $i$ iskrenih tragalaca za istinom.

Učenicima El-Evza'ija se ne smije prebacivati da su zanemarili njegov mezheb, pa je to bio razlog njegovog nestanka. Zaključujemo da su oni dali prednost istini i argumentu, a ne slijepom fanatizmu, što je svakako vrlina.

3. Možda bi se mogla uzeti u obzir dodatna činjenica da su pisana djela imama El-Evza'ija izgorjela u zemljotresu 130. hidžretske godine, kako navodi imam Zehebi u djelu Sijer e'lamin-nubelâ', u kojem je na Ahiret preselio i veliki broj Ensarija.

Imam Zehebi bilježi izreku Muhammed b. 'Avfa, koji kaže da je čuo Hišama b. 'Ammara, a on Velida - da je rekao: "U zemljotresu je izgorijelo petnaest El-Evza'ijevih knjiga. “'19 On također navodi da mu je neka osoba donijela primjerke njegovih knjiga da ih pregleda $\mathrm{i}$ odobri, mada to on nikada nije uradio.

4. Među razlozima koji bi se mogli navesti jeste i slaba rasprostranjenost kodificiranja naučnih djela u to vrijeme, $\mathrm{s}$ obzirom da je kodofikacija, npr. Poslanikove biografije, uzela maha tek za vrijeme tabi'ina, kako to navodi dr. Mustafa Siba'i u Poslanikovom životnom putu. ${ }^{20}$

5. Neki istraživači smatraju da su El-Evza'ijev mezheb potisnuli drugi rasprostranjeniji mezhebi, kao što su četiri poznata mezheba, tako da niko više nije pridavao važnost mišljenjima koja su potisnuta sa naučne scene.

\footnotetext{
${ }^{18}$ Eš-Ša'ar Mervan Muhammed, El-Evza 'i - prvak prvih generacija, Darun-Nefa'is, Bejrut, 1992.

${ }^{19}$ Sijer e'lamin-nubelâ', 7/114-115.

${ }^{20}$ Dr. Siba'i Mustafa, Poslanikov životni put, str. 12-13 (prevod sa arapskog Ahmet Alibašić, bez godine i mjesta izdavanja).
} 
Tako je, npr., mezheb imama El-Evza'ija potisnuo u Šamu šafijski mezheb, dok ga je u arapskom Magribu i Andaluziji potisnuo malikijski mezheb. ${ }^{21}$

Ovo su samo neki razlozi do kojih smo došli u istraživanju, iako su to, kako smo rekli, sve puste pretpostavke koje se ne mogu naučno argumentovati.

Također, nije isključeno da je više ovih tačaka zajedno stvarni razlog nestanka mezheba koji bi, u slučaju da je stigao do nas, bio jedno veliko bogatstvo i predmet istraživanja narednih generacija.

\section{Neki primjeri fikhskih stavova imama El-Evza ija}

Prije nego navedemo nekoliko primjera fikhskih stavova imama El-Evza'ija, smatram da bi bilo korisno navesti metodologiju koju je koristio ovaj uglednik prilikom crpljenja fikhskih propisa.

Ono što se dâ zaključiti jeste da je imam El-Evza'i prezirao analogno crpljenje propisa (kijas) i najviše se oslanjao na tradiciju ili predaje koje se prenose od Poslanika, s.a.v.s., ili njegovih ashaba. ${ }^{22}$ Šta više, sam imam El-Evza'i je bio muhaddis i prenosilac hadisa. Njegovu opredijeljenost za tradiciju možemo zaključiti i iz njegovih izreka, od kojih bih istakao sljedeću: "Drži se predaja koje se prenose od prvih generacija, makar te ljudi odbacili. Čuvaj se proizvoljnih stavova, makar bili ukrašeni i uljepšani. “23

Primjeri njegovih pojedinih fikhskih stavova su:

\section{Pitanje padanja nečistoće}

Ibn Abdil-Berr prenosi konsenzus da se, ako u čvrstu masu padne mrtva životinja, strvina odstranjuje, kao i ono gdje je pala, tj. oko nje. Što se tiče stvari koje su u tečnom stanju, postoji razilaženje: većina učenjaka smatra da ta masa postaje u cijelosti nečista samim dodirom sa nečistoćom, dok imami Ez-Zuhri i El-Evza'i smatraju da svaka stvar u tečnom stanju ima propis vode, tj. da postaje nečistom

${ }^{21}$ Hudari Muhammed, Historija islamskog zakonodavstva, str. 179, Darul-kutubil'ilmijjeti, drugo izdanje, Bejrut, 1994.

22 Ibid.

${ }^{23}$ El-Bidajetu ven-nihaje, str. 10/126. 
samo ukoliko se promijeni. To je ujedno mišljenje Ibn Abbasa, Ibn Mes'uda i Buharija. ${ }^{24}$

2. Pitanje sumnje u svitanje zore da li postač treba jesti ukoliko nije siguran da je zora svanula

Ibn Abbas, Ata, Ahmed i El-Evza'i smatraju da mu je dozvoljeno jesti sve dok ne bude uvjeren da je zora svanula. ${ }^{25}$

3. Pitanje da li je osoba koja ispunjava uslove za obaveznost hadždža, obavezna da ga odmah obavi, ili to može odgađati

Imam Šafija, Sevri, Muhammed b. Hasan i imam El-Evza'i smatraju da se hadždž može odgoditi, tj. može se obaviti bilo kad u životu, s tim da ako osoba umre i ne obavi ga, postaje grješna.

Međutim, Ebu Hanife, Malik, Ahmed, pojedine šafije i Ebu Jusuf smatraju da je obaveza obavljanje hadždža neodložna! $!^{26}$

4. Pitanje klanjanja dženaze namaza pobačenom dijetu

Takvo dijete se, po konsenzusu svih učenjaka, ukoliko nije navršilo četiri mjeseca, ne gasuli niti mu se klanja dženaza namaz, nego se zamota u krpu i zakopa. Ukoliko je navršilo četiri mjeseca ili više i pusti glas, u tom slučaju se, po konsenzusu, gasuli i klanja mu se dženaza.

Međutim, ukoliko ne pusti glas, učenjaci su se po tom pitanju razišli. Hanefije, malikije i imam El-Evza'i smatraju da mu se ne klanja dženaza, dok Ahmed i Ibn Sîrîn smatraju da se gasuli i da mu se klanja dženaza. ${ }^{27}$

\footnotetext{
${ }^{24}$ Sabik Sejjid, Fikhus-sunne, prvo izdanje, Darul-Feth lil-i'lamil-'arebi, str. 1/35, Kairo, 1996.

${ }^{25}$ Fikhus-sunne, str. 1/600.

${ }^{26}$ Fikhus-sunne, str. 1/636-637.

${ }^{27}$ Fikhus-sunne, str. 1/399.
} 
Ko je o njemu pisao detaljne studije?

Od istaknutih prethodnika o imamu El-Evza'iju pisali su mnogi, međutim većina njih je to radila u sklopu djela o biografijama prenosilaca hadisa ili uglednim fikhskim velikanima.

Od rijetkih koji su biografiji ili naučnom radu imama ElEvza'ija posvetili posebnu pažnju bili su:

Prvo: Imam Šafija je napisao djelo Sijerul-Evza i $i$, u kojem je spomenuo mišljenja Ebu Hanife i Evza‘ijev odgovor.

U ovom djelu imam Šafija govori o pitanjima usko vezanim za rat poput uzimanja oružja iz ratnog plijena, primjene šerijatskih kazni (hudûd) u dârul-harbu ${ }^{28}$, uništavanja drveća koje pripada neprijatelju, pitanja o ženi koja primi islam u dârul-harbu, itd.

Jakub b. Jusuf, poznatiji kao Ebu Jusuf, najpoznatiji učenik imama Ebu Hanife, napisao je djelo Er-Reddu 'ala sijeril-Evza'i (Odgovor na djelo 'Sijerul-Evza 'i').

Drugo: Salih b. Jahja, autor djela Historija Bejruta, napisao je posebno djelo o imamu El-Evza'iju kako nam to prenosi Hajruddin Zirikli u El-E 'lamu. ${ }^{29}$

Od potonjih autora najviše pažnje izučavanju života i djela imama El-Evza‘ija posvetio je šejh Muhammed eš-Ša'ar, koji je napisao dvije studije.

Prva: "El-Evza' $i$ - prvak prvih generacija“"

$\mathrm{U}$ ovom djelu autor pokušava da rasvijetli značajnu ulogu koju je svojevremeno imao ovaj uvaženi velikan, njegov životni i naučni put.

Druga: "El-Evza ijev sunen - hadisi, predaje i fetve“, u kojoj je sakupio 2.210 hadisa koje imam El-Evza'i prenosi, 85 predaja i sedam fetvi i mišljenja uglednog imama. ${ }^{30}$

Šejh Muhammed eš-Ša'ar je u 808 strana sakupio sve dostupne predaje i poredao ih po fikhskim temama, tako da se ovo djelo, $\mathrm{s}$ pravom, može smatrati jednim od najvrjednijih djela koja govore o ovom islamskom velikanu.

\footnotetext{
${ }^{28}$ Darul-harb (ar.) zemlja rata, područje izloženo borbenim dejstvima, područje u kojem se muslimanima ne sudi Šerijatom te u kojem muslimani nemaju adekvatnu zaštitu.

${ }^{29}$ El-E'lam, str. 3/320.

${ }^{30}$ Siretul-imam el-Evza 'i,www.middleeasttransparent.com
} 
Ova knjiga je svoje prvo izdanje doživjela 1993. godine u izdavačkoj kući En-Nefa'is u Bujrutu.

Pored šejha Muhammeda eš-Ša'ara, koji je uložio svoj trud da ova dva djela osvjetle El-Evza'ijevu ličnost, dr. Abdullah Muhammed el-Džebburi napisao je studiju o životu imama El-Evza'ija i odbranio je 1977. god. kao doktorsku disertaciju na Fakultetu za fikh i pravo Univerziteta El-Azhar u Kairu.

Ova doktorska disertacija ili studija se sastoji od dvaju tomova u kojima autor obrađuje sljedeće teme:

1. biografija i fikh imama El-Evza'ija

2. propisi vezani za ibadet (obredoslovlje)

3. propisi vezani za poslovanja među ljudima. ${ }^{31}$

Drugi o ітати El-Evza ‘iju

Ukoliko bismo željeli da citiramo sve izreke prvih i potonjih generacija o ulozi, renomeu i reputaciji imama el-Evza'ija, ovaj bi rad promijenio svoju dimenziju, pa ćemo odabrati najistaknutije izreke najpoznatijih učenjaka.

Tako imam Malik b. Enes, jedan od njegovih učenika, veli: "El-Evza'i je imam na kojeg se treba ugledati.

Salih b. Jahja u djelu Tarihu Bejrut veli: "Imam El-Evza'i je uživao veliki ugled u Šamu do te mjere da je bio ugledniji od sultana. “33

Ebu 'Amr eš-Šami ed-Dimeški je rekao: "El-Evza'i je bez dvojbe prvak i najugledniji učenjak Šama svoga vremena. ${ }^{\text {‘34 }}$

U istom kontekstu dolaze i riječi Sufjana b. 'Ujejne koji veli: "El-Evza' $i$ je bio najugledniji učenjak svoga vremena."

Hafiz Ibn Kesir o njemu kaže: "Kad god bi nešto rekao, svi prisutni bi se osjećali da su, zbog ljepote izgovorenih riječi, primorani

\footnotetext{
${ }^{31}$ El-Džebburi dr. Abdullah Muhammed, Mevsû 'atu fikhil-imami El-Evza'i, DarulFikr, pro izdanje, Bejrut.

${ }^{32}$ El-Bidajetu ven-nihaje, str. 10/125.

${ }^{33}$ El-E'lam, str. 3/320.

${ }^{34}$ Abdur-Rahman el-Evza'i, el-alimul-murabit, http://www.fustat.com/bibliography/awzai.shtml

${ }^{35}$ Abdur-Rahman el-Evza i, el-alimul-murabit, http://www.fustat.com/ bibliography/ awzai.shtml
} 
da zabilježe izrečene riječi ““36 On također bilježi da su drugi kazali: "Kada bi drugima pričao o vjeri, niko ne bi ostao da ne zaplače okom ili srcem. ${ }^{\text {‘37 }}$

\section{Istinski i odvažni učenjak}

Mnoštvo je primjera veličine koja je krasila imama ElEvza'ija. Teško je pokušati ih pobrojati, mada se mogu izdvojiti neki od primjera koji će nam tu veličinu ilustrirati.

Jedan od najilustrativnijih primjera jeste slijedeći događaj. Naime, imam El-Evza'i je, pod utjecajem neprovjerenih vijesti o Ebu Hanifi, donosio sasvim negativne zaključke o njemu, iako se s njim nije nikad susreo. Jedne prilike upitao je Abdullaha b. el-Mubareka, Ebu Hanifinog učenika: "Ko je čovjek iz Kufe, zvani Ebu Hanife, koji uvodi novotarije/bid'ate?" Abdullah b. el-Mubarek mu nije direktno odgovorio, već mu je navodio precizna i utemeljena šerijatskopravna rješenja, na što ga je on upitao: "Ko je autor tako savršenih fetvi?"“

Odgovorio je: "To je učenjak koga sam sreo u Iraku!“ ElEvza'i mu je tada rekao: "On je izvrstan učenjak! Idi i druži se s njim što više!" Tada mu je Ibn el-Mubarek priznao: "To je Ebu Hanife!"

Nakon izvjesnog vremena u Mekki su se sreli El-Evza‘i i Ebu Hanife i raspravljali o pitanjima koja je spominjao Ibn el-Mubarek nakon čega je El-Evza'i priznao Ibn el-Mubareku: "Ogovarao sam čovjeka obilnog znanja i izuzetne inteligencije. Molim Allaha da mi oprosti! Bio sam u očitoj zabludi! Obavezno slijedi tog čovjeka, jer ovo u što sam se uvjerio kod njega je suprotno onome što sam čuo! ‘38

Drugi primjer nam bilježi Ibn Kesir, a radi se o susretu sa amidžom Abdullaha b. Alija Es-Seffaha u Damasku. El-Evza'i priča: "Ušao sam kod njega i zatekao ga kako sjedi na krevetu. U ruci je imao štap, a sa njegove desne i lijeve strane su stajali vojnici u crnini sa isukanim sabljama. Nazvao sam mu selam, na koji mi nije odgovorio. Mahnuo je štapom i rekao: 'Evza'i, šta misliš o onome što smo učinili na preuzimanju vlasti od nasilnika koji su tlačili zemlju i robove? Je li to džihad?' Emire, čuo sam Jahju b. Seida, koji prenosi

\footnotetext{
${ }^{36}$ El-Bidajetu ven-nihaje, str. 10/124.

${ }^{37}$ El-Bidajetu ven-nihaje, str. 10/124.

${ }^{38}$ Dr. Kurdić Šefik, Ebu Hanifin doprinos hadiskoj nauci, časopis Novi Horizonti, br. 10 , juni 2000 , str. 16 .
} 
od Alkame b. Vekkasa, a ovaj od Omera b. el-Hattaba, koji prenosi od Poslanika, sallallahu alejhi ve sellem, da je rekao: 'Djela se vrednuju prema namjeri; svakoj osobi pripada ono što namjeri."“

Abdullah b. Ali je udario štapom jače nego prvi put, a vojnici su stisli sablje. Zatim je rekao: „Evza'i, a šta kažeš za umejevićku krv?“ „Poslanik, sallallahu alejhi ve sellem, rekao je: 'Nije dozvoljeno da se muslimanska krv prolijeva osim u tri slučaja: odmazda za ubistvo, kad oženjen ili udata učine zinaluk i kad se čovjek odmetne od svoje vjere,' " odgovori El-Evza'i. „Šta kažeš za njihove imetke?“", upita emir. „Ako su njihovi imeci stečeni na haram način, i tebi su onda haram, a ako su stečeni na dozvoljen način, tebi su dozvoljeni samo na dozvoljen način, rekao sam. Tada je udario štapom tako jako da sam očekivao da mi glava padne među šake (tj. mislio sam da će mi je odsjeći), a onda mi je naredio da iziđem.“

Treći primjer: Nekoliko stanovnika Libana usprotivilo se namjesniku Aliji b. Abdillahu b. Abbasu, koji im se silom suprotstavio i izvojevao pobjedu. Smatrao je da bi bilo mudro da ih rastavi iseljavajući neke od njih iz njihovih kuća u druga mjesta, što bi bilo prirodno da uradi bilo koji vođa najciviliziranijih naroda današnjice.

Kada je za to saznao imam El-Evza'i, mudžtehid i učenjak iz Šama, napisao je namjesniku Libana pismo u kojem osuđuje njegov postupak sa Libancima, koje je iselio iz njihovih sela, i kaznio one koji nisu učestovali u ustanku. Između ostalog mu je napisao i slijedeće: "Ti dobro znaš da je među zimmijama ${ }^{39}$ koje si protjerao sa planine Liban bilo onih koji nisu podržavali taj ustanak, neke si ubio, a ostale povratio njihovim selima, pa kako da kazniš sve radi greške pojedinaca i tjeraš ih sa njihovih ognjišta i imetaka. Allahov propis je: 'da nijedan grješnik tuđe grijehe neće nositi' ${ }^{40}$, a slijeđenje onoga što On kaže i neprelaženje Njegovog propisa je ispravnije i prječe. Najprječe oporuke kojih se treba držati su oporuke Božijeg Poslanika, s.a.v.s., koji je rekao: 'Ko štićeniku islamske države, nemuslimanu (zimmiji) učini nepravdu ili optereti ga iznad njegovih mogućnosti, ja

\footnotetext{
39 Zimmija (ar.) - nemusliman koji živi u islamskoj državi i uživa određene povlastice u odnosu na muslimane (plaćanje zekjata, vojna služba itd.)

${ }^{40}$ Kur'an, En-Nedžm, 38.
} 
ću mu biti protivnik na Sudnjem danu $?^{41}$ Kada je namjesnik Libana primio pismo, povratio je iseljene u njihova sela uz sve počasti. “42

Četvrti primjer je izreka koju bilježi hafiz Ibn Kesir kako je jedan od namjesnika halife El-Mensura rekao na njegovom kaburu: "Neka mu se Allah smiluje, jer, tako mi Allaha, više sam se bojao njega od samog El-Mensura koji me je postavio na mjesto namjesnika. ${ }^{* 43}$

\section{Neke od izreka imama El-Evza ‘ija}

U samom uvodu ovoga rada spomenuli smo da je ovaj naš velikan bio praktičar, a pod tim smo mislili da je bio uporan da sve ono što je znao primijeni u praksi. Tako se prenosi da je dosta činio ibadet i jako lijepo obavljao namaz. Ustezao se od sumnjivih situacija i bio predanog srca svom Gospodaru. Malo je govorio. Imao je običaj da kaže: "Ko dugo klanja noćni namaz, Allah, dž.š., će mu smanjiti dužinu stajanja na Sudnjem danu. “44

Iz njegovih nastupa se da zaključiti da je bio ustrajan na istini, pridržavajući se Poslanikove, s.a.v.s., upute. Hafiz Ibn Kesir nam u tom kontekstu bilježi njegovu sljedeću izreku: "Drži se predaja koje se prenose od prvih generacija, makar te ljudi odbacili. Čuvaj se proizvoljnih stavova, makar bili ukrašeni i uljepšani،““5 Također bi govorio: "Ustraj u pridržavanju sunneta i stani ondje gdje su drugi stali. Reci ono što su oni kazali, a prešuti ono što su oni prešutjeli.“46

\section{Zaključak}

Imam el-Evza'i je bio vrstan velikan i veliki praktičar onoga što je poznavao.

Živio je u vrijeme tabi‘ina, osoba koje su drugovale sa ashabima, drugovima Božijeg Poslanika, s.a.v.s., što mu je dalo priliku da nauku crpi sa njenih izvora. Iako je to vrijeme bilo

\footnotetext{
${ }^{41}$ Bilježi ga Ebu Davud.

${ }^{42}$ Dr. Siba'i Mustafa, Fenomeni islamske civilizacije, Islamski pedagoški fakultet u Bihaću, 2005, str.116-117.

${ }^{43}$ El-Bidajetu ven-nihaje, str. 10/128.

${ }^{44}$ El-Bidajetu ven-nihaje, str. 10/126.

45 Ibid.

46 Ibid.
} 
blagoslovljeno zbog spomenute činjenice, bilo je puno izazova i previranja spram kojih se naš velikan znalački postavio.

Nismo kategorički ustvrdili koji je razlog iščezavanja njegovog mezheba, ali se dâ pretpostaviti da je to više raznih okolnosti. Međutim, to ne umanjuje njegov naučni ugled, niti marljivost njegovih najprisnijih učenika koji su prednost dali istini i argumentu.

Svako o njemu govori punim ustima hvale, pa čak ga neki smatraju prvakom i najvećim naučnim velikanom epohe u kojoj je živio.

Od njega nam se prenose četiri knjige o fikhu i sijeru, a oni koji su se najviše posvetili osvjetljavanju njegove biografije i naučnog stvaralaštva bili su šejh Muhammed Mervan eš-Ša'ar i dr. Abdullah Muhammed el-Džebburi.

\section{Literatura:}

1. Dr. Buzugajbe Muhammed, Siretul-imam el-Evza'i, www. middleeasttransparent.com/old/texts/mohamed_buzghuiba_aw zaii_sira.htm

2. El-Džebburi dr. Abdullah Muhammed, Mevsû́ 'atu fikhil-imami El-Evza $i$, Darul-Fikr, prvo izdanje, Bejrut

3. Ibn Kesir Ebul-Fidâ', El-Bidajetu ven-nihaje, Darul-hadis, Kairo, 1993.

4. Dr. Kurdić Šefik, Ebu Hanifin doprinos hadiskoj nauci, časopis Novi Horizonti, br. 10, juni 2000.

5. El-Kejlani Ismail, Abdur-Rahman el-Evza'i, el-alimul-murabit, www.fustat.com/ bibliography/awzai.shtml

6. Sabik Sejjid, Fikhus-sunne, Darul-Feth lil-i'lamil-'arebi, prvo izdanje, Kairo, 1996.

7. Dr. Siba'i Mustafa, Fenomeni islamske civilizacije, Islamski pedagoški fakultet u Bihaću, 2005.

8. Dr. Siba'i Mustafa, Poslanikov životni put (prevod sa arapskog Ahmet Alibašić, bez godine i mjesta izdavanja)

9. Eš-Ša'ar Mervan Muhammed, El-Evza'i - prvak prvih generacija, Darun-Nefa'is, Bejrut, 1992.

10. Ez-Zehebi Šemsuddin, Sijer e'lamin-nubelâ', Muesseseturrisale, jedanaesto izdanje, Bejrut

11. Zirikli Hajruddin, El-E‘lam, Darul-ilm lil-melâjîn, 11. izdanje, Bejrut, 1995. 
HAJRUDIN HODŽIĆ, B.A.

\section{IMAM EL-EVZA'I - OVERSHADOWED FIQH LEADING FIGURE (88 - 157. H.)}

\section{SUMMARY}

This work deals with biography and scientific opus of one of the greatest Islamic scholars and fiqh experts, imam El-Evza'i.

Apart from speaking about his career and scientific reputation, this work pinpoints sayings of his contemporaries about him, about his teachers and disciples, and in the end there are a few examples showing his brave and extraordinary personality.

One of the main goals of this work is an attempt to answer the question: Why did the «mezheb» of imam Evza'i disappear, although its founder was one of the greatest and leading figh experts.

Value of this work lies in the fact that only a little is written about Islamic great people in Bosnian language, and almost nothing is written about imam El-Evza'i. 


$$
\text { الأستاذ خير الدين هوجيتش }
$$

$$
\text { الملخص }
$$

يتتاول هذا البحث سيرة ومكانة علمية لأحد أكبر علماء وفقهاء الإسلام الإمام الأوز اعي.

إضافة إلى الكلام عن سيرته ومنزلته العلمية ، فقد أفرد البحث قسماً تتاول حديث

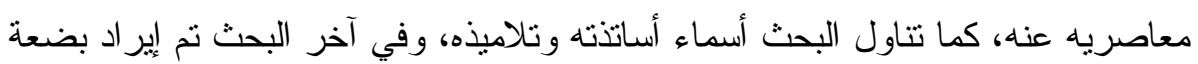
أمنلة لشخصيته الصامدة و الجريئة. لقد كان من أهم أهداف هذا البحث محاولة الإجابة على السؤال التالي: لماذا اندثر

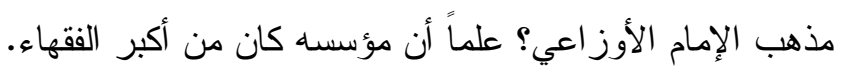
أهمية هذا البحث تكمن في أن الكتابة عن عظماء الإسلام باللغة البوسنوية نادرة جداً، وخاصة أن الثخصيات، كأمثال الإمام الأوز اعي، كانت شبه مجهولة النه 